\title{
En busca de un mundo mejor... Una reflexión ética desde América Latina
}

German R. Rosa Borjas, S.J.

Universidad Centroamericana, San Salvador

RESUMEN: El autor plantea una reflexión ética de la situación socioeconómica latinoamericana, a partir de los desafíos de la globalización. Para ello, se dialoga críticamente con algunos postulados del economista y filósofo Karl Popper, en particular, sobre su punto de vista de las sociedades abiertas.

ABSTRACT: The author poses an ethical meditation on the socio-economic situation in Latin America, through the challenge of globalization. In order to achieve this, the author critically dialogues with some of the postulates of the economist and philosopher Karl Popper, in particular, with his point of view on "open societies".

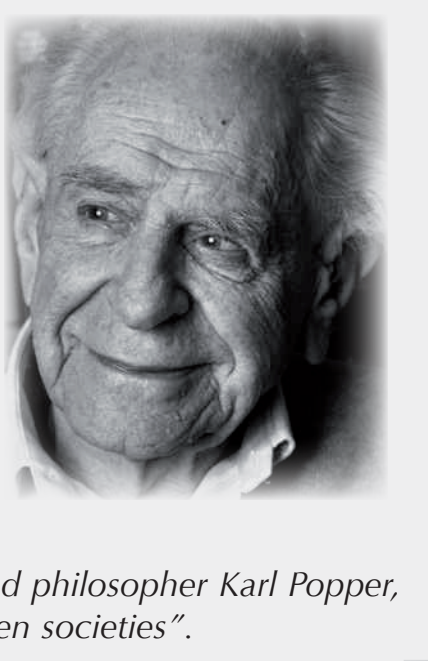




\section{Introducción}

os tratados de libre comercio en Centroamérica son una nota sobresaliente en el nuevo milenio que hemos comenzado. Los países centroamericanos tienen gobiernos democráticos, han aplicado las medidas de los ajustes estructurales y de liberalización de la economía, se han privatizado gran parte de los servicios públicos $y$, sin haber logrado una verdadera integración regional, se han incorporado a las dinámicas de una apertura comercial, exigencia de las dinámicas de la globalización económica y financiera.

Los países centroamericanos cada vez más están orientados a la configuración de una amplia sociedad abierta a los mercados, los capitales transnacionales y las relaciones políticas occidentales. Y cada vez más se están abriendo a nuevas relaciones con países del lejano y cercano oriente. Los argumentos que se esgrimen en los medios de comunicación social son los siguientes: las aperturas traen inversiones extranjeras, transferencias de tecnologías, hay una expansión de los mercados nacionales, esto lleva al crecimiento económico y en consecuencia lograremos un mayor bienestar social. Si no participamos de estas aperturas comerciales seremos sociedades cerradas y nos quedaremos rezagados ante los grandes cambios que trae la globalización económica y financiera. Hay que dar el paso a las aperturas comerciales y financieras de la globalización... Este es un imperativo en la economía y las finanzas en la actualidad.

\section{La configuración de América Latina desde la óptica de la sociedad global}

$\left.1^{\circ}\right)$ Crecimiento económico y concentración de la riqueza.

El circuito de la globalización ha generado una distribución asimétrica y desproporcionada en el mundo; vamos constituyendo un tejido social vulnerable globalmente:

$\checkmark$ El Programa de las Naciones para el Desarrollo ha publicado datos importantes al respecto: “En 1960, el 20\% más rico de la población mundial registraba ingresos treinta veces más elevados que los del 20\% más pobre. En 1990, el 20\% más rico estaba recibiendo sesenta veces más". ${ }^{1}$

$\checkmark$ Si distribuyéramos el Producto Mundial Bruto en 4 partes, nos daríamos cuenta de las grandes asimetrías y grandes desproporciones. En 1995 el 89\% del Producto Mundial Bruto le correspondía al $25 \%$ que constituye el sector más rico de la población mundial, mientras que al $75 \%$ de la población mun- 
dial le correspondía solamente el $11 \%$ restante. La situación es más dramática cuando nos damos cuenta que al 25\% más pobre le correspondía tan sólo el 1,43\% del Producto Mundial Bruto. $^{2}$

$\boldsymbol{\sim}$ Hay progreso en el contexto de una economía mundial cada vez más próspera, pero 10,7 millones de niños no viven para celebrar su quinto cumpleaños y más de 1,000 millones de personas sobreviven en condiciones de abyecta pobreza con menos de un dólar al día. ${ }^{3}$

$\checkmark$ Hay una desproporción creciente entre el crecimiento económico, la distribución del ingreso y la pobreza en el mundo: "El ingreso total de 500 individuos más ricos del mundo es superior al ingreso de los 416 millones más pobres. Más allá de estos extremos, los 2.500 millones de personas que viven con menos de dos dólares al día $-y$ que representan el $40 \%$ de la población mundialobtienen sólo el $5 \%$ del ingreso mundial. El 10\% más rico, casi todos ellos habitantes de los países de ingresos altos, consigue el $54 \% "{ }^{\prime 4}$

Esta tendencia de la concentración de la riqueza se concreta en América Latina de la manera siguiente:

\section{Distribución del Ingreso en América Latina, 2002}

\begin{tabular}{|c|c|}
\hline $\begin{array}{c}\text { Población en } \\
\text { Porcentaje (\%) }\end{array}$ & $\begin{array}{c}\text { Porcentaje (\%) del Ingreso Nacional Total que } \\
\text { recibe cada sector de la población }\end{array}$ \\
\hline $20 \%$ & $54,24 \%$ \\
\hline $60 \%$ & $40,81 \%$ \\
\hline $20 \%$ & $4.71 \%$ \\
\hline
\end{tabular}

Fuente: CEPAL, Unidad de Estadísticas Sociales, División de Estadísticas y Proyecciones Económicas.

$2^{\circ}$ ) Políticas económicas-sociales y la tarea pendiente de superar la pobreza en Centroamérica.

La década de los 80 significó políticamente la democratización de América Latina, la privatización de los activos nacionales y el creciente protagonismo de los mercados. ${ }^{6}$ En Centroamérica la democracia era una respuesta a los fenómenos revolucionarios y supuso el viraje necesario de gobiernos militares a gobiernos civiles, de esta manera se han hecho intentos de aplicar políticas económicas y sociales para resolver los factores explicativos de estos fenómenos sociales. No obstante, el segundo informe sobre el desarrollo humano de Centroamérica y Panamá, elaborado por el Programa de las Naciones Unidas para el Desarrollo (PNUD), arrojan datos interesantes. 


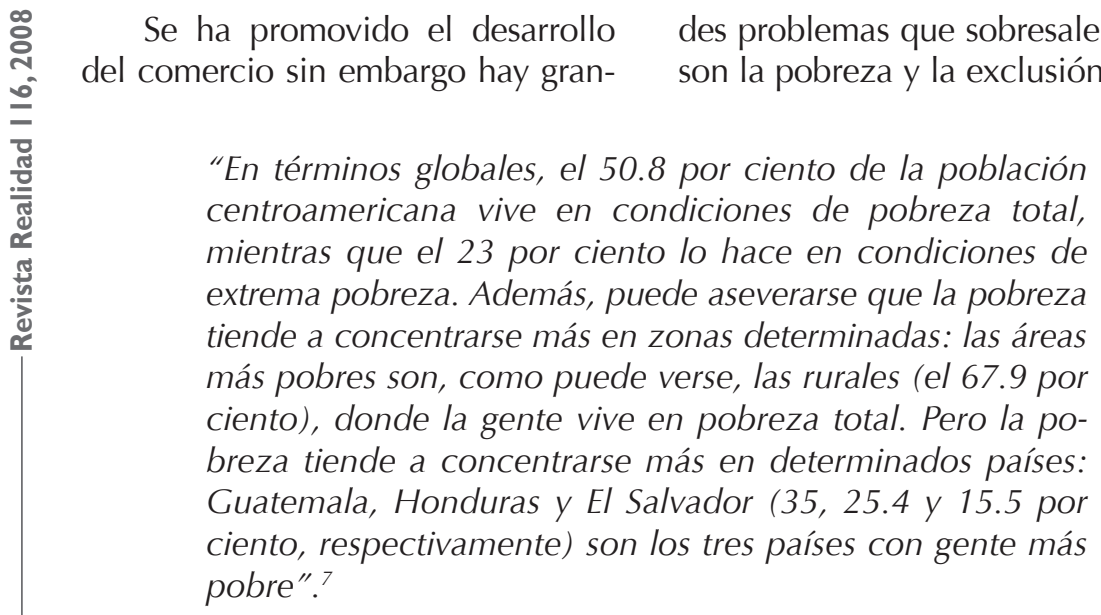

Se puede percibir que el desarrollo económico ha excluido grandes sectores sociales en la región:

"¿En qué medida el estilo de desarrollo predominante en Centroamérica favorece la exclusión? En la misma medida en que las políticas económicas que lo sustentan relegan el desarrollo humano de las mayorías. Baste con ver el cuadro comparativo sobre el gasto público. El gasto público social de países como Argentina, Brasil y Uruguay es superior al 20 por ciento del PIB. En naciones como El Salvador, Guatemala y Honduras equivale al 4.3, 6.2 y 7.4 por ciento, respectivamente". ${ }^{8}$

En Costa Rica los indicadores de generación de ingreso, pobreza, empleo y pensiones, que nos muestran la distribución de oportunida-

des en la población han evolucionado de forma claramente negativa en el año 2005:

"La pobreza media por ingreso pasó de 18,5\% a 21,7\%. Esto se traduce en 38,000 hogares pobres, aproximadamente un millón de personas. Medida según las necesidades básicas insatisfechas, la pobreza representa 36\% de los hogares y afecta a uno de cada tres costarricenses. La situación es peor en el área metropolitana del centro del país y en la región sur. Se registró una caída de $6 \%$ en el ingreso per cápita promedio de los hogares, mientras los salarios mínimos reales experimentaron un descenso". ${ }^{\prime 9}$ 
El caso de Honduras muestra alguna leve mejoría en términos de pobreza, según la fuente del PNUD, "el porcentaje de pobres bajó de 80,5\% en 1990 a 79,1\% en 1997. Entre 2002 y 2004, la extrema pobreza pasó de $49 \%$ a $44,6 \%$, mientras que el nivel general de pobreza se redujo a $64 \%{ }^{\prime \prime} .{ }^{10}$ Aunque se destaca una notable diferencia y desigualdad económica y política entre los géneros: "De los siete millones de habitantes que se estima tiene Honduras, 51\% son mujeres. De ellas, al menos 7 de cada 10 son pobres. En el censo de 2003 se registraron 1.262 .020 hogares, 25\% de los cuales están a cargo de una mujer". ${ }^{11}$

El Presidente de El Salvador ha expresado que ha habido una notable reducción de la pobreza en el país, entre 1991 y 2004, de 33\% a $15 \%$. Sin embargo, el PNUD ha cuestionado el método oficial de estimar la pobreza, y se le ha señalado al gobierno que no toma en cuenta a las personas pobres que son "expulsadas del país" y sostienen la economía nacional con sus remesas:

\begin{abstract}
"Las remesas, que en 2005 superaron USD 2.830 millones, permiten a muchas familias satisfacer sus necesidades básicas. La Comisión Económica para América Latina y el Caribe (CEPAL) y el PNUD han señalado que las remesas alivian la pobreza entre $7 \%$ y $8 \%$. Datos de la Universidad Centroamericana establecen que cada año emigran unas 145.000 personas, con un total de 2,8 millones de salvadoreños y salvadoreñas en el exterior, una cifra equivalente a la cuarta parte de la población" ${ }^{12}$
\end{abstract}

Las remesas vienen a servir de colchón para amortiguar las necesidades básicas de los grupos pobres en El Salvador. La mayor parte de las remesas sirven para acceder a bienes y servicios de primera necesidad. ${ }^{13}$

Hay un aspecto de suma importancia. En Centroamérica se puede invertir más en el gasto social y es recomendable. Si nos ponemos analizar este aspecto en el caso de El Salvador, "Entre 1996 y 2003, los fondos destinados a desarrollo social aumentaron de 4,7\% a 7,3\% del PIB. En educación, pasaron de
$2,2 \%$ a $3,1 \%$, pero en salud solamente de $1,4 \%$ a $1,5 \%$ del PIB. El Banco Mundial ha expresado que para que los pobres se beneficien del programa económico es necesaria mayor inversión social, la cual es factible" ${ }^{14}$

La Comisión Económica para América Latina (CEPAL) en su informe de la situación social de la región: Panorama social de América Latina 2006, califica que se ha tenido un mejor desempeño económico y social durante el período 20032006 en los últimos 25 años: 
"En sintonía con el FMI, la CEPAL sostiene que en los últimos cuatro años se ha reducido el desempleo y mejorado la distribución del ingreso gracias a la expansión económica de Latinoamérica. Sin embargo, a pesar de los avances en la lucha contra la pobreza, se deben de tomar en cuenta en el análisis la baja calidad de los nuevos empleos generados y la inestabilidad económica de la región". ${ }^{15}$

No cabe duda que la tendencia es una distribución asimétrica del ingreso en Latinoamérica también:

"Otro aspecto que destaca el informe de CEPAL es la distribución de los ingresos en la región. Según las diversas encuestas de los países latinoamericanos, el estrato social conformado por el $40 \%$ de los hogares con menor capacidad adquisitiva capta, en promedio, un $14 \%$ del ingreso total. Por otro lado, el $50 \%$ de los hogares que se ubican en la zona media y media alta de la estructura de la distribución del ingreso - estrato social con un nivel de ingreso por encima del estrato anterior - capta alrededor del $50 \%$ del total de ingresos generados en el país. El 10\% de hogares restantes - el estrato social más rico - obtiene un 36\% del ingreso total". ${ }^{16}$

Queda mucho trecho por recorrer para resolver el problema de la pobreza y de la exclusión social en la región centroamericana.

$3^{\circ}$ ) La necesidad de auténticos Estados de bienestar social en la región centroamericana

En un contexto en que los Estados nacionales van perdiendo cancha frente a los mercados internacionales y el comercio global, dada esta realidad de empobrecimiento no podemos eludir el tema de la necesidad de constituir auténticos Estados de bienestar social en Centroamérica, tal como lo expresa Karl Popper este surge de una convicción moral humanitaria.
Esto no puede hacernos olvidar que una burocracia excesiva tiene sus costos sociales también y no se puede justificar. Sin embargo, para un desarrollo social y económico sostenible es necesaria una activa participación de los Estados centroamericanos y no solamente de los mercados abiertos al comercio internacional.

Si el estado de bienestar demostró ser incapaz de generar gran redistribución de la riqueza y las rentas, sin embargo, ayudó a promover una clase media en expansión consolidando el sector intermedio de la sociedad. ${ }^{17}$ Pero con la crisis del Estado de bienestar las capas medias se han empobrecido, 
dado la aplicación de medidas de ajuste estructural y la liberalización de la economía en la región centroamericana.

Aunque las desigualdades económicas no han sido resueltas con el Estado de bienestar, si ha ocurrido una disminución de las mismas. El Estado de bienestar no ha sido tan eficaz en términos de la redistribución, pero ha favorecido en gran parte la participación de la clase media con los beneficios de los programas sociales. No podemos ignorar que: "La pobreza se ha visto aliviada, sobre todo, no por la redistribución de los más acomodados hacia los más pobres, sino por los incrementos generales de la riqueza que han hecho ascender a todo el mundo. Así ha sido tanto en las sociedades escandinavas, con los programas de bienestar más visiblemente desarrollados, como en los demás lugares" ${ }^{18}$

Una de las conquistas más importantes del Estado de bienestar ha sido la generalización del seguro social, sobre todo su extensión a lo largo de toda la vida.

Dicho esto, nos parece importante destacar que no proponemos revivir el Estado de bienestar del siglo pasado, sino replantear la necesidad de un auténtico Estado de bienestar desde una perspectiva distinta que garantice una verdadera redistribución de la renta generada y de los riesgos de manera más equitativa en la sociedad centroamericana. El Estado de bienestar es necesario replantearlo desde una perspectiva distinta frente al gran protagonismo de los mercados y del comercio global.

Si la globalización nos plantea el tema de la gobernabilidad para que exista una convivencia pacífica, de tal manera que se puede pensar en una confederación de Estados o bien en la constitución de un Estado global, vale la pena pensar desde nuestro contexto, en la constitución de un Estado de bienestar social regional.

$4^{\circ}$ ) Karl Popper destaca que la democracia es la forma de gobierno que más ha beneficiado a la humanidad y esto puede ser extensivo también a la sociedad global.

En América Latina, la democracia tiene grandes desafíos. Los datos que aparecen en la tabla siguiente sistematiza las opiniones de 152 entrevistados, que constituye una parte del universo poblacional de la ronda de consultas a 231 líderes latinoamericanos, incluidos 41 presidentes y vicepresidentes, además hay una distribución de la muestra que recoge la opinión de líderes de la sociedad civil, religiosos, sindicalistas, empresarios y militares. ${ }^{19}$ 


\section{Agenda actual según tema ${ }^{20}$}

(Se elaboró en base a 152 entrevistados que respondieron las preguntas sobre el tema)

\begin{tabular}{|c|c|c|}
\hline Tema & $\begin{array}{l}N^{\circ} \text { de Actores que } \\
\text { mencionan }\end{array}$ & Porcentaje \\
\hline \multicolumn{3}{|l|}{ Agenda Económica } \\
\hline $\begin{array}{l}\text { La reactivación de la economía (debate sobre } \\
\text { el uso de recursos productivos: gas, petróleo, } \\
\text { coca; privatizaciones, reforma financiera) }\end{array}$ & 80 & $53 \%$ \\
\hline Cuestión fiscal & 24 & $16 \%$ \\
\hline Deuda externa & 9 & $6 \%$ \\
\hline $\begin{array}{l}\text { Integración regional andina /MERCOSUR/ } \\
\text { ALCA }\end{array}$ & 9 & $6 \%$ \\
\hline Tratados de libre comercio & 8 & $5 \%$ \\
\hline Acuerdos con el FMI & 3 & $2 \%$ \\
\hline \multicolumn{3}{|l|}{ Agenda Social } \\
\hline Desempleo & 52 & $34 \%$ \\
\hline Violencia, delincuencia, seguridad ciudadana & 51 & $34 \%$ \\
\hline Reforma de la educación / salud & 40 & $26 \%$ \\
\hline Pobreza & 37 & $24 \%$ \\
\hline \multicolumn{3}{|l|}{ Agenda Política } \\
\hline La corrupción & 55 & $36 \%$ \\
\hline $\begin{array}{l}\text { Reforma política / Papel de los partidos / } \\
\text { Descentralización }\end{array}$ & 30 & $20 \%$ \\
\hline Reforma del Estado (apertura, modernización) & 23 & $15 \%$ \\
\hline $\begin{array}{l}\text { Resolución del conflicto político institucional } \\
\text { / Reconstrucción institucional / Debilidad } \\
\text { institucional }\end{array}$ & 12 & $8 \%$ \\
\hline $\begin{array}{l}\text { Lavado de dinero y narcotráfico. El tema de la } \\
\text { coca }\end{array}$ & 12 & $8 \%$ \\
\hline $\begin{array}{l}\text { Reforma del sistema judicial. Estado de } \\
\text { derecho. Seguridad jurídica }\end{array}$ & 11 & $7 \%$ \\
\hline Reforma constitucional & 9 & $6 \%$ \\
\hline $\begin{array}{l}\text { Relación gobierno - sociedad, conciliación } \\
\text { nacional }\end{array}$ & 6 & $4 \%$ \\
\hline
\end{tabular}

Fuente: PRODDAL, Ronda de consultas con líderes de América Latina, 2002. 
La siguiente tabla expresa la opinión ciudadana en torno a la agenda que debe seguir la democracia en América Latina. Aparecen seis temas principales por resolver y que es importante tomar en cuenta para un ejercicio auténtico de democratizar el continente.

\section{La Agenda Ciudadana: principales problemas. \\ Promedio América Latina, 2002 ${ }^{21}$}

\begin{tabular}{|l|c|}
\hline \multicolumn{1}{|c|}{ Temas por resolver } & Población en \% \\
\hline Problemas de empleo & 34,63 \\
\hline Pobreza, desigualdad e ingreso insuficiente & 26,33 \\
\hline Delincuencia y drogas & 11,88 \\
\hline Violencia política & 7,53 \\
\hline Servicios e infraestructura insuficiente & 6,76 \\
\hline Corrupción & 11,34 \\
\hline Otros & 1,53 \\
\hline
\end{tabular}

Fuente: PRODDAL, Latinoamérica 2002.

Todas estas problemáticas ponen de relieve que la democracia y la economía de mercado han tenido sus impacto y tienen sus grandes demandas en el presente. Hay grandes exigencias de eficacia en la gobernabilidad y en la economía de los países latinoamericanos.

$\left.5^{\circ}\right)$ La eficacia del capitalismo en la sociedad red global.

Hoy por hoy vivimos en un mundo en el que por primera vez en la historia las relaciones humanas están determinadas con asombrosa eficacia por el sistema capitalista en todo el planeta. ${ }^{22}$ Hay transformaciones insólitas en la economía global como por ejemplo lo que ocurre con la versión China de estatismo. El Partido Comunista ha permitido la incorporación de China al capitalismo global, basándose en un proyecto nacionalista representado por el Estado. Hay un proceso de adaptación a la sociedad red global. ${ }^{23}$

¿Qué es la sociedad red?

Vivimos en la era de la información, la cual fluye a la velocidad de la luz a través de redes modificando sustancialmente los procesos de producción, la experiencia, el poder y la cultura. El poder de los flujos de información son de alcance global. La sociedad red global tiene una morfología social bien definida y a pesar de que está fragmentada en muchos ámbitos y dimensiones personales y sociales, al mismo tiempo está articulada por un conjunto de nodos interconectados: 
"Un nodo es el punto en el que una curva se intersecta a sí misma. Lo que un nodo es concretamente, depende del tipo de redes a que nos refiramos. Son los mercados de la bolsa y sus centros auxiliares de servicios avanzados en la red de los flujos financieros globales. Son los consejos nacionales de ministros y los comisarios europeos en la red política que gobierna la Unión Europea. Son los campos de coca y amapola, los laboratorios clandestinos, las pistas de aterrizajes secretas, las bandas callejeras y las instituciones financieras de blanqueo de dinero en la red del tráfico de drogas que penetra en economías, sociedades y Estados de todo el mundo. Son los canales de televisión, los estudios de filmación, los entornos de diseño informático, los periodistas de los informativos y los aparatos móviles que generan, transmiten y generan señales en la red global de los nuevos medios que constituyen la base de la expresión cultural y la opinión pública en la era de la información". ${ }^{24}$

La distancia física, social, económica, política y cultural, es superada por la articulación de los flujos de información entre los nodos, las redes y la arquitectura de las relaciones entre estos ámbitos antes aludidos. Todo esto se facilita por las tecnologías de la información operando a la velocidad de la luz y que van configurando los procesos y funciones dominantes en nuestra sociedad. ${ }^{25}$

En la sociedad global los sujetos que hegemonizan los cambios y las transformaciones apenas se les puede vislumbrar el rostro porque dichos actores son casi imperceptibles. Sin embargo, esto nos plantea el problema sobre qué tipo de sociedad queremos construir, tema sobre el cual Karl Popper ha tratado en su libro en busca de un mundo mejor. Tal parece que el mundo en que vivimos se nos presenta como el mejor de los mundos posibles y nos confronta con el gran desafío de cuestionarlo para transformarlo y reorientar grandes procesos globales.

Una sociedad abierta con el dinamismo que engendra la búsqueda de un mundo mejor, expresa someramente el contexto en que estamos inmersos en la actualidad. Karl Popper es autor de dos obras que precisamente nos dice en sus títulos lo que hemos considerado que expresa la situación actual o nuestro contexto: a) La sociedad abierta y sus enemigos; b) En busca de un mundo mejor.

Haremos una lectura crítica de estas obras retomando algunas intuiciones audaces de Karl Popper que nos ayudan a pensar los grandes cambios globales. Por esta razón, retomamos algunas pinceladas de su pensamiento plasmado en las dos obras antes mencionadas, luego haremos algunas críticas a dicho 
planteamiento. Hemos elegido esta autor liberal porque nos parece emblemático de posturas económicas y políticas que son bastante afines al planteamiento de este autor. Muchas veces se argumenta con el planteamiento de Karl Popper sin saberlo, aunque no se diga expresamente que se retoma este modo de pensar para configurar la realidad sociopolítica y económica en la región centroamericana. Hay otra razón importante, Karl Popper fue un autor visionario en su contexto, sin embargo hay consecuencias y situaciones que escaparon a su planteamiento y que es importante destacar haciendo una lectura desde la realidad latinoamericana porque arroja luces sorprendentes que pueden iluminarnos para construir el mejor de los mundos posibles.

La sociedad abierta

La sociedad abierta es la que ha superado la situación y condición de sociedad cerrada:

"Una de las características que definen la actitud mágica de una sociedad 'cerrada', primitiva o tribal, es la de que su vida transcurre dentro de un círculo encantado de tabúes inmutables, de normas y costumbres que se repuntan tan inevitables como la salida del sol, el ciclo de las estaciones $u$ otras evidentes uniformidades semejantes de la naturaleza. La comprensión teórica de la diferencia que media entre la 'naturaleza' y la 'sociedad' sólo pueden desarrollarse una vez que esa 'sociedad cerrada' mágica ha dejado de tener vigencia". ${ }^{26}$

En el pensamiento de K. Popper, la sociedad cerrada se encuentra en tensión dinámica con la sociedad abierta, identifica la sociedad cerrada con la sociedad mágica, tribal o colectivista, y la sociedad abierta la concibe como aquella en que los individuos deben adoptar decisiones personales. ${ }^{27}$

\section{2) La transición de la sociedad cerrada a una sociedad abierta.}

a sociedad abierta la piensa Karl Popper en tensión dialéctica con la sociedad cerrada. Analicemos aspectos importantes de esta transición de la sociedad cerrada a la sociedad abierta. 
vínculos semibiológicos, tales como el parentesco, la convivencia, la participación equitativa en los trabajos, peligros, alegrías y desgracias comunes. Los individuos tiene relaciones sociales físicas, concretas, mediadas por el tacto, el olfato, la vista. ${ }^{28}$ Mientras que en la sociedad abierta, se caracteriza porque los miembros se esfuerzan por elevarse socialmente, y de este modo, pasan a ocupar los lugares de otros miembros. Esto puede conducir a fenómenos como la lucha de clases. ${ }^{29}$

La sociedad abierta puede convertirse gradualmente en una sociedad abstracta. Es posible que los hombres no se encuentren cara a cara, sus relaciones están mediatizadas por comunicaciones telefónicas, telegráficas, sin encontrarse se trasladan en vehículos privados, dicho brevemente, el retrato de nuestra sociedad moderna se parece a esta sociedad abstracta despersonalizada. ${ }^{30} \mathrm{Si}$ queremos elevar a su máxima expresión esta categoría de K. Popper, la sociedad abierta global es la sociedad abstracta de la informática, la telemática y de los multimedia en la que la realidad virtual tiene una densidad que muchas veces sustituye la verdadera realidad.

b) La transición arranca con los cambios ocurridos en la cultura griega - helenista.

El paso de la sociedad cerrada a la sociedad abierta es una de las revoluciones más profundas experimentadas por la humanidad. Esto tiene grandes repercusiones socioculturales: "los griegos iniciaron para nosotros una formidable revolución que, al parecer, se halla todavía en sus comienzos: la transición de la sociedad cerrada a la abierta". ${ }^{31}$

K. Popper concibe también la sociedad abierta como aquella en la que se da el paso a la legalidad:

"La teoría convencionalista de la legalidad no es algo aislado sino una muestra más de la revolución que significa el paso a la sociedad abierta, revolución que tuvo lugar en Grecia, especialmente en Atenas a lo largo del siglo V a.C. Una revolución que fue tanto intelectual como política, y que se refleja en el nacimiento de la democracia, primero, y de la filosofía, después, como respuesta a los problemas que precisamente plantea, en el orden social e intelectual, la fractura del monismo tribal". ${ }^{32}$

El propósito de la obra de K. Popper, La sociedad abierta y sus enemigos, el autor la expresa en estos términos:

"la empresa de construir una sociedad abierta que rechace la autoridad absoluta de lo establecido por la mera fuerza del hábito y de la tradición, tratando por el contrario, de 
preservar, desarrollar y establecer aquellas tradiciones, viejas o nuevas, que sean compatibles con las normas de la libertad, del sentimiento de la humanidad y de la crítica racional. La voluntad de estos seres no es quedarse cruzados de brazos, dejando que toda la responsabilidad del gobierno del mundo caiga sobre la autoridad humana o sobrehumana, sino compartir la carga de la responsabilidad o los sufrimientos evitables y luchar para eliminarlos. Esta revolución ha creado temibles fuerzas de destrucción, pero esto no impide que el hombre llegue a conquistarlas para el bien, en un futuro no lejano". ${ }^{33}$

La sociedad abierta está estructurada desde un racionalismo crítico individualista. ${ }^{34}$ Hoy el problema que se plantea es precisamente cómo superar un individualismo para alcanzar una sociedad global solidaria y resolver los problemas fundamentales que nos afectan universalmente.

La sociedad abierta se da con el paso del hombre que piensa superando así el dogmatismo tribal. Los miembros de la tribu, según este pensador, raramente dudan de su forma de actuar, están determinados por tabúes, por instituciones tribales mágicas que nunca pueden ser objeto de consideración crítica, las instituciones basadas en la tradición colectiva de la tribu no dejan lugar a la responsabilidad personal.

La sociedad abierta surge con el individuo que se independiza de la totalidad y gana sobre ella su soberanía: "Es el principio que mejor define a la sociedad abierta: el individualismo, en virtud del cual cada individuo es el principio de su propia determinación". ${ }^{35}$ Karl Popper sostiene que el individualismo es la base de nuestra civilización occidental.

La sociedad abierta irrumpe en la práctica con nuevos valores, nuevas normas, engendra un nuevo humanismo. ${ }^{36}$ Ocurre el surgimiento de una nueva fe en el hombre, en la justicia igualitaria y en la razón humana. ${ }^{37}$ Otro rasgo de la sociedad abierta además del individualismo es el amor a la libertad. ${ }^{38}$

c) Karl Popper nos ofrece un programa de la sociedad abierta.

La sociedad abierta global nos plantea desafíos ineludibles. Karl Popper nos sugiere todo un programa interesante para nuestro mundo de hoy:

"Los hombres no son iguales, pero a nosotros nos concierne la decisión de luchar por derechos iguales. Las instituciones humanas como el estado no son racionales, pero nosotros mismos podemos decidir luchar para darles una racionalidad progresiva. Nosotros mismos y nuestro lenguaje ordina- 
rio somos, en conjunto, más sentimentales que racionales; pero podemos tratar de ganar en racionalidad, y podemos acostumbrarnos a utilizar nuestro lenguaje como un instrumento, no de autoexpresión (como dirían nuestros románticos educadores) sino de comunicación racional". ${ }^{39}$

Karl Popper ha desarrollado su planteamiento sobre la sociedad abierta de manera amplia y nosotros retomamos esta intuición filosófica moral, también lo hacemos desde una perspectiva crítica asumiendo el criterio de falsabilidad que nos aporta dicho autor. ${ }^{40}$ Tal parece que la propuesta desde nuestro mundo occidental y occidentalizado es la constitución de una sociedad abierta articulada por una macro red en todo el planeta, es decir, la sociedad abierta global, la sociedad abierta democrática liberal y de libre mercado.

\section{3) ¿Por qué Karl Popper opta por una sociedad abierta?}

A sus 87 años de vida escribe Karl Popper: "A pesar de todo, y aunque hemos tenido tantos fracasos, nosotros, los ciudadanos de las democracias occidentales, vivimos en un orden social que es mejor (porque está más favorablemente dispuesto a la reforma) y más justo que cualquier otro de la historia conocida. Son de la máxima urgencia nuevas mejoras. (Pero las mejoras que aumenta el poder del Estado a menudo producen lo contrario de lo que estamos haciendo)" ${ }^{41}$

Karl Popper asumiendo una postura optimista, sostiene que ha disminuido la terrible pobreza masiva que existía en el período de su niñez y juventud excepto en lugares como Calcuta, sin inquietarle mucho la concentración del ingreso mundial nos dice: "Algunos pueden objetar que hay personas en nuestra sociedad demasiado ricas. Pero ¿por qué nos ha de importar, si hay suficientes recursos - y la buena voluntad - para luchar contra la pobreza y otros sufrimientos evitables?". ${ }^{42}$

\section{La visión crítica de Karl Popper sobre la sociedad abierta y sus matices.}

Aunque Karl Popper es un fiel defensor de la sociedad abierta occidental, pondera muy bien que existen cosas buenas y malas. Lo que nos muestra su esfuerzo de objetividad para proponer el modelo de sociedad abierta.

El proyecto de la sociedad abierta lo concibe rechazando todo tipo de despotismo y chantaje, en particular, el chantaje por amenaza de guerra. La sociedad abierta es libre y pacífica: "Creemos que la invención de la bomba atómica fue una calamidad terrible" ${ }^{\prime 4}$ 
Karl Popper no deja al margen los riesgos reales de nuestro tiempo y reconoce el consenso de los pensadores contemporáneos al respecto:

"vivimos en una época miserable, en una época positivamente criminal, posiblemente la peor de todas las épocas conocidas; que estamos caminando el borde del abismo; y que la causa de esto es nuestra perversión, quizás incluso nuestro pecado original. Nos hemos vuelto inteligentes, dice Bertrand Russell (a quien tengo en mucha estima), quizá demasiado inteligentes; pero por lo que respecta a la moralidad, no somos suficientemente buenos. Desgraciadamente, nuestra inteligencia se ha desarrollado más rápido que nuestra conciencia moral. Así, hemos sido lo suficientemente inteligentes para construir bombas atómicas y de hidrógeno; pero moralmente hemos sido demasiado inmaduros para construir un Estado mundial, lo único que nos puede salvar de una guerra de aniquilación a escala mundial". ${ }^{44}$

De ahí que retoma con seriedad la búsqueda de un mundo mejor. Desde su punto de vista la democracia liberal es el camino aceptable y se constituye en modelo del quehacer político y económico de nuestro mundo hoy.

Karl Popper es ciertamente un filósofo convencido al proponer su proyecto de sociedad abierta: "Afirmo que, a pesar de todo, nuestra época es la mejor de que tenemos conocimiento histórico y que el tipo de sociedad en que vivimos en occidente es, a pesar de sus fallos, el mejor que ha existido hasta la fecha". ${ }^{45}$

Veamos los argumentos que fundamentan su propuesta:

a) Entre los argumentos que sustentan dicha creencia K. Popper menciona el repunte económico de la posguerra con el incremento de la producción, la generación de riqueza y el mejoramiento de la calidad de vida en occidente, en donde casi ha desaparecido la pobreza. De hecho la lucha contra la pobreza ha sido constante para acabar con el hambre, también destaca el hecho que la sociedad abierta ofrece las mejores oportunidades de vida o "igualdad de oportunidades".

b) Otro argumento importante es ofrecer a todos la posibilidad de estudios universitarios. Además se ha incrementado el consumo, hay nuevas necesidades y la ambición de posesiones. Karl Popper reconoce el peligro de esta situación, pero destaca que sin ello es inevitable la pobreza generalizada. ${ }^{46}$

c) La lucha contra la pobreza ha llevado a la constitución del 
Estado de bienestar con una monstruosa burocracia, sin olvidar que éste surge de una convicción moral sumamente humanitaria. La crítica del Estado de bienestar debe estar orientada a mejorar formas para materializar estas intuiciones morales. La educación superior es un derecho adquirido que se da por supuesto.

d) El aumento de las demandas materiales ha conllevado consecuencias no deseables tales como la insatisfacción constante y la envidia en vez de la satisfacción al compararse con los demás. ${ }^{47}$

Karl Popper llega a plantear que la ambición económica de las masas es un medio para superar la pobreza por su propio esfuerzo individual y evitar el crecimiento de la burocracia del Estado de bienestar y su creciente tutela del individuo: "Sólo la ambición económica individual puede volver tan rara la pobreza que llegue a ser absurdo hacer de la lucha contra la pobreza el principal objetivo del Estado". ${ }^{48}$

En definitiva, la tutela del Estado se traduce en la pérdida de la libertad individual. Desde esta perspectiva, el planteamiento de Karl Popper se decanta por la sociedad occidental, en pro de la economía de mercado y en contra de la economía planificada centralizada:

"personalmente, creo que una economía libre de mercado es más eficiente que una economía planificada; pero considero totalmente erróneo basar el rechazo de la tiranía en argumentos económicos. Aun si fuese verdad que una economía planificada estatal centralizada es superior a la de libre mercado, me opondría a la economía planificada; por la simple razón de que con ésta es probable que aumente el poder del Estado hasta llegar a la tiranía. Lo que combatimos no es la ineficiencia del comunismo, sino su falta de libertad y humanidad". 49

De esta manera, la democracia es el correlato político de una economía de libre mercado en la sociedad abierta, la cual define Karl
Popper como la forma de gobierno menos mala, con el matiz determinante de salvaguardar la libertad política:

"Creemos pues en la democracia, pero no porque sea el gobierno del pueblo. Ni ustedes ni yo gobernamos; por el contrario, tanto ustedes como yo somos gobernados, y en ocasiones más de lo que desearíamos. Pero creemos en la democracia como forma de gobierno compatible con la oposición política y efectiva, y por ello con la libertad política". ${ }^{50}$ 
Aunque él insiste que con frecuencia las mayorías toman decisiones equivocadas, también destaca que las minorías tienen derechos y libertades que no pueden invalidar ninguna decisión mayoritaria. ${ }^{51}$

\section{Algunos cabos sueltos de la socie- dad abierta que se va globalizando y que es importante no obviarlos.}

La sociedad abierta globalmente deja cabos sueltos que es importante sacar a luz:

a) Las distintas tendencias liberales convergen en considerar el Estado como un mal necesario, aunque se deben limitar sus poderes y éstos no deben multiplicarse más allá de lo necesario. ${ }^{52}$ La sociedad global abierta cada vez más muestra la pérdida de la soberanía de los estados nacionales y su pérdida notable de control correctivo ante los grandes problemas que se suscitan de cara a las dinámicas del mercado y del gran capital que no tienen controles ni restricciones de cara a la población en general.

b) Karl Popper destaca que la democracia es la forma de gobierno que más ha beneficiado a la humanidad y esto puede ser extensivo también a la sociedad global ${ }^{53}$ : "La libertad de pensamiento y la libre discusión son valores supremos que en realidad no necesitan ulterior justificación" ${ }^{54}$ Sin embargo en la democracia "global" preva- lentemente se ésta favorecido más el ejercicio del sufragio y la libertad de expresión, queda mucho trecho por recorrer para realizar una mayor participación económica con equidad de los ciudadanos en la sociedad global. Nunca hubo antes tal concentración de riqueza y una pobreza inmensa como existe hoy en el planeta.

c) La institucionalidad de la justicia es puesta en cuestión cuando el marco moral exige una justicia distributiva al subsistema político - jurídico, dada la extensión y el incremento desproporcionado de la pobreza y sus secuelas en el mundo.

d) La crítica al modelo democrático liberal y la economía de mercado.

Al plantearnos la cuestión de la sociedad abierta global nos cuestiona la propuesta de Karl Popper en su obra en busca de un mundo mejor. No se trata de resolver un enigma por pura actividad lúdica de la razón o del interés individual para sentir la satisfacción gratificante de quien ha llegado a una verdad arduamente buscada, como si se tratara de una varita mágica que resuelve los problemas globales. Ciertamente que en América Latina, la democracia liberal y la economía de mercado no han sido tan eficaces ni reformables, más aún, cada vez más hay un creciente cues- 


\begin{tabular}{|c|}
\hline $\begin{array}{l}\text { tionamiento a las mismas desde } \\
\text { el ejercicio de la política y tam- } \\
\text { bién desde la reflexión teórica } \\
\text { por lo que estamos interpelados } \\
\text { a buscar una sociedad global } \\
\text { más humana y solidaria. }\end{array}$ \\
\hline
\end{tabular}

\section{Núcleos de problemas que plantea la sociedad abierta.}

Algunos núcleos de problemas no resueltos en la sociedad abierta que se va configurando.

a) El crecimiento económico es inviable universalmente.

El crecimiento económico es de vital importancia, pero si lo relacionamos con el hábitat en el que estamos inmersos, las posibilidades son limitadas para que dicho crecimiento económico sea universalizable, además se perciben los límites y el impacto del mismo en los ecosistemas y la asimétrica distribución de la renta generada en la sociedad abierta global. Todo esto si queremos que haya una correspondencia entre la realidad y el conocimiento de la misma, tal como lo expresa Kant, en esto consiste el conocimiento verdadero: "la correspondencia del conocimiento con su objeto".$^{55}$

b) El desafío de una praxis política con veracidad y transparencia.

La pregunta planteada en la República de Platón sigue vigente en la sociedad abierta liberal y de libre mercado: ¿Quién debe gobernar? Una respuesta apresurada, a la manera de responder un catecismo de filosofía moral sería, obviamente que los sabios y los filósofos, sin embargo, esta respuesta obvia lo que ocurre con las mayorías, los empobrecidos, los excluidos de los círculos del poder político y económico y también culturales de la sociedad red abierta globalmente.

Karl Popper, formula la cuestión platónica tratada en la República de otra manera, que nos resulta ingeniosa y con mucha sagacidad para nuestros países latinoamericanos: "¿quiénes deben ser nuestros gobernantes: los capitalistas o los trabajadores?". 56 Sin embargo, él reformula la cuestión de una manera totalmente diferente: “¿cómo podemos organizar nuestras instituciones políticas de forma que los gobernantes malos o incompetentes (a los cuales, por supuesto, hemos de intentar evitar, pero que de todos modos podemos tener) nos causen sólo el mínimo daño?". ${ }^{57}$

Esto nos lleva inevitablemente a rescatar la veracidad y transparencia en el ejercicio de la política, es decir, haciendo de la política un ejercicio de la verdad con transparencia que se opone a la mentira, la demagogia, la manipulación de la realidad y de las situaciones más importantes de la vida de los ciudadanos. Cosa que no se logra siempre en las contiendas electorales o durante los períodos de gobierno de los partidos políticos que se hacen en el poder. Muchas veces, la imagen distorsiona lo que en verdad ocurre en la realidad. La 
verdad objetiva como exigencia de la praxis política es un valor ético, quizás uno de los mayores valores que exista.

c) El choque cultural una puerta abierta al mutuo enriquecimiento de los pueblos.

Al pensar en los procesos de aperturas comerciales y la globalización de las relaciones socioeconómicas, políticas y culturales, no se nos escapa el hecho que supone el trauma de estos procesos, no obstante Karl Popper nos subraya que los choques culturales no necesariamente resultan siempre ser violentos, éstos pueden dar lugar a un vertiginoso renacimiento cultural, al descubrir lo específico y, al mismo tiempo, valorar que los ethos y las tradiciones culturales no son resultado de un orden natural, sino producto histórico y de la evolución de las civilizaciones. ${ }^{58}$

El choque cultural, lejos de sumirnos en una guerra fraticida si hay una actitud de diálogo y encuentro $^{59}$, puede ayudarnos al desarrollo sorprendente de la creatividad y la solidaridad para asumir los dramas y las tragedias de la humanidad. Dar lugar al encuentro aún en el contexto del impacto que supone la apertura y las transformaciones que supone la globalización, nos pueden hacer pensar sobre la posibilidad de un enriquecimiento cultural sin precedente, pero sin justificar tendencias nacionalistas impositivas que busquen eliminar otras identidades culturales, o bien sea, la pretendida absolutez fundamentalista de hacer un mundo a la medida etnocéntrica de quien se lo imagina y se lo fabrica...

Más que choque violento de civilizaciones o los choques culturales, hoy es más importante hablar de diálogo entre las culturas, es decir, propiciar el mutuo enriquecimiento cultural, la cooperación solidaria para romper con la espiral de la violencia del mundo actual, resolver los graves problemas de la miseria y la exclusión social que deshumaniza y enfatizar la mutua aceptación tolerando la pluralidad y la diversidad multicultural.

El peligro real de la sociedad abierta global en nuestro contexto es subsumir la pluralidad de cosmovisiones aplastando otras civilizaciones, que de suyo no son occidentales, lo cual sería incurrir en una imposición muchas veces bélica del occidente o bien de la sociedad occidentalizada.

Al buscar un mundo mejor, la convivencia universal puede ser una experiencia novedosa y fecunda para resolver los grandes problemas y los dramas de la humanidad.

Vivimos en una sociedad latinoamericana que va dando lugar progresivamente a la apertura de las fronteras económicas, política, sociales y culturales organizada en una red global. No pretendemos decir ingenuamente que actualmente América Latina constituye 
un conjunto de sociedades tribales, cerradas, porque de hecho ya han sufrido grandes transformaciones desde la colonización con todas sus implicaciones, el impacto de la modernidad y se perciben ya algunos rasgos de una transición a la posmodernidad. No obstante, las culturas indígenas tienen grandes aportes que hacer a la sociedad occidental y occidentalizada.

Un ejemplo claro de esta transición de la modernidad a la posmodernidad es lo que ocurre en la economía actualmente. En la sociedad moderna occidental económicamente predomina el libre mercado, la propiedad privada, los paradigmas del individualismo y el utilitarismo. Esto es más evidente después de la caída del muro de Berlín. En la sociedad posmoderna surge la "Nueva Economía" basada en la alta tecnología, ocurre la globalización y se ha ido confirmando la brecha que existe entre dos mundos: una economía formal y los excluidos de ella que conforman el mundo de la economía informal. De esta manera, se observa el incremento ascendente de la pobreza global concomitante a una alta concentración del ingreso global. ${ }^{60}$ En América Latina hay rasgos de la modernidad y también de la posmodernidad.

Karl Popper nos arroja muchas luces con su planteamiento de la sociedad abierta, sin embargo, podemos hacer algunas observaciones que consideramos oportunas. Partimos del presupuesto que es importante reconocer, de manera somera, los grandes aportes de la modernidad. Según nuestra opinión es importante rescatar los valores del pleno reconocimiento de la dignidad y la autonomía humana, el reconocimiento de los derechos humanos, el desarrollo tecnológico y científico, la revolución cultural instaurada por la ilustración, etc. Dicho esto, procedemos a expresar nuestras observaciones críticas.

a) Su planteamiento crítico con respecto al Estado y su monstruosa burocracia, nos hace pensar que en el actual contexto el protagonismo del mercado ha dejado al margen al Estado y, en consecuencia, las inmensas mayorías están abandonadas a su suerte. La unidad rectora que estructura las relaciones sociales es el mercado. Si lo vemos desde la participación activa que ha tenido el Estado en la reconstrucción europea de la posguerra, el mejoramiento social que ha generado, no podemos justificar el abandono de la sociedad a las fuerzas del mercado. Hay que recuperar el rol regulador del Estado para lograr un equilibrio con las fuerzas del mercado, sin inflar la burocracia, para relanzar el desarrollo social y cultural de la sociedad latinoamericana, porque la liberalización de los mercados no ha resuelto los problemas de la pobreza, el desempleo, ni de la exclusión social. Se ha complicado y se han generado otros problemas 
graves como por ejemplo las migraciones masivas.

b) Karl Popper critica el historicismo que lo definió como: "un punto de vista sobre las ciencias sociales que supone que la predicción histórica es el fin principal de éstas, y que supone que este fin es alcanzable por medio del descubrimiento de los 'ritmos' o los 'modelos', de las 'leyes' o las 'tendencias' que yacen bajo la evolución de la historia". ${ }^{61}$ Dicho de manera sucinta: "el historicismo nos dice que la meta o fin hacia el cual se está moviendo la historia es moralmente deseable porque la historia se está moviendo en una cierta dirección" ${ }^{62}$ No obstante su crítica, Karl Popper en su planteamiento nos presenta la sociedad abierta como el resultado de la evolución histórica de las civilizaciones. Al plantear la sociedad abierta con sus logros y sus límites, dentro del esquema lineal de la historia, considera que todas las sociedades calificadas de cerradas y todas las culturas, necesariamente evolucionan dentro de los límites teleológicos de una gran sociedad abierta global, como una ley ineluctable de la historia. Situación grave que atenta en contra de un mundo y un universo pluri-cultural, pluriétnico. De ahí que la necesidad del diálogo entre las culturas y entre los pueblos es una tarea urgente, pero en posiciones de simetría para que no se imponga el esquema de una sociedad abierta como la panacea y el modelo universal que configurará todas las sociedades y culturas. No podemos obviar también los límites reales de la sociedad abierta.

c) La visión lineal de la historia de la sociedad abierta calza bien con el esquema desarrollista de la sociedad liberal. En nuestro contexto latinoamericano, la concepción desarrollista ha sido cuestionada y criticada precisamente por la perspectiva crítica de la teoría de la dependencia y el subdesarrollo que genera el desarrollo socioeconómico.

d) Al aplicar el criterio de falsación a todos los logros de la sociedad abierta señalados por Karl Popper, nos damos cuenta que algunos de ellos no son alcanzables sin la acumulación originaria de las riquezas de pueblos y culturas más allá de las fronteras de la misma Europa y del primer mundo, no hay que olvidar los temas pendientes de la alta concentración del ingreso en términos globales y el modelo industrial que atenta en contra de los ecosistemas y la ecología del planeta, los cuales responden al modelo de crecimiento económico liberal; es más, la sociedad abierta es asimétrica y legitima las diferencias sociales, políticas, económicas y culturales. Siendo más perjudicados aquellos que constituyen el conjunto de las Ilamadas sociedades cerradas. 


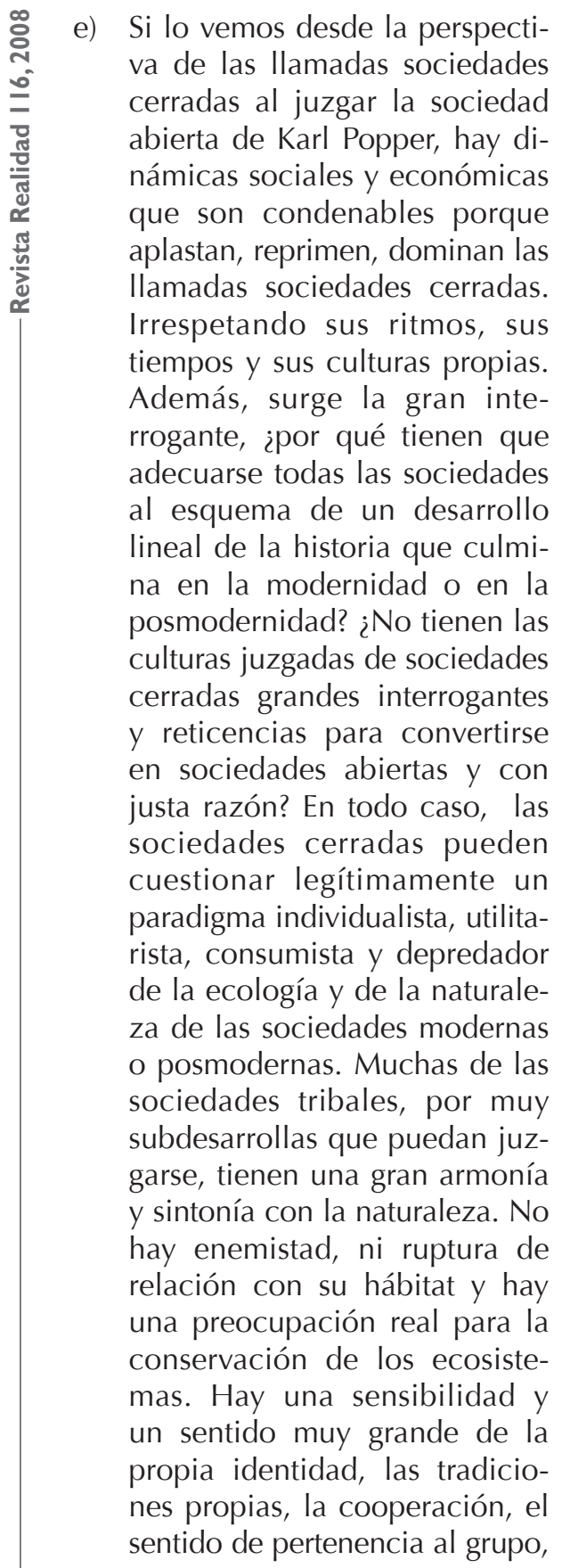

clan o tribu, una solidaridad en las relaciones de producción, distribución y consumo de los productos, etc. Valores que muchas veces están ausentes en "la sociedad global".

f) Al proponer la sociedad abierta moderna como un paradigma eurocéntrico desde el cual se juzgan todas las culturas, se plantea una visión etnocéntrica, que tiene graves consecuencias para las culturas precolombinas, la pluralidad étnica, con el grave peligro de imponer una visión única y homogénea universal.

g) La modernidad irrumpe en nuestros pueblos y continentes con luces y sombras, beneficios incuestionables pero también con la estela de la violencia, cuando se ha ido expandiendo desde posturas dominantes $y$ muchas veces discriminatorias, menospreciando la riqueza de las culturas autóctonas, hay una dosis de violencia con la irrupción de la modernidad al imponerse en las sociedades cerradas o tribales. De todo ello no habla Karl Popper en sus planteamiento de la sociedad abierta propuesta como la sociedad mejor del mundo que él ha pensado.

h) Una cosa importante que no aparece en el planteamiento de Karl Popper sobre la sociedad abierta es que las culturas y las civilizaciones tienen mitos fundacionales. 


\section{¿Qué es un mito?}

Se llama mito a un relato fabuloso que nos remite a un pasado: "Los mitos pueden referirse a grandes hechos heroicos (en el sentido griego de 'heroicos') que con frecuencia son considerados como el fundamento y el comienzo de la historia de una comunidad o del género humano en general" ${ }^{63}$

Los mitos son tradiciones, son constitutivos de las culturas y de las civilizaciones. No hay cultura o civilización que no tenga sus mitos: "La formación de mitos obedece a una especie de necesidad inherente a la cultura, de modo que los mitos pueden considerarse como supuestos culturales" ${ }^{64}$

No olvidemos cómo los griegos explican el origen del universo mediante relatos y mitos. Al principio, existía el caos o el Vacío. El caos era una inmensa vacua, negra y oscura, en la que nada se veía, una especie de abismo, ciego, oscuro e ilimitado. Después apareció la tierra o Gea y nace posteriormente al caos, se puede definir a Gea "como aquello sobre lo cual los dioses, los hombres y los animales pueden caminar con soltura. Es el suelo del mundo". ${ }^{65}$ Desde otra perspectiva, la cultura hebrea semítica explica el origen del universo en el libro del Génesis con relatos míticos (Gn 1-2), que intentan expresar la realidad.

Las divinidades poblaron la cultura griega - helenista. Uno de los más conocidos es Zeus que es el dios del cielo y soberano de los dioses olímpicos. ${ }^{66}$ Zeus también es un símbolo de filosofía moral griega: "En la obra del poeta griego Homero, Zeus aparece representado de dos maneras muy diferentes: como dios de la justicia y la clemencia y como responsable del castigo a la maldad". ${ }^{67}$ Zeus aparece en la mitología griega como el garante del orden cósmico, de la justicia, como el salvador y castigador de la impiedad, dicho brevemente, la divinidad universal. ${ }^{68}$ No olvidemos que en culturas ancestrales, los dioses gobiernan la tierra y tiene grandes influjos sobre el poder político.

Baste recordar en la Apología de Sócrates la acusación que hacen contra el filósofo: y se resumen de esta manera: "Sócrates es culpable de corromper a los jóvenes, de no reconocer a los dioses del Estado y de introducir nuevas divinidades" ${ }^{69}$

Se le acusa de incredulidad y negar la existencia de las divinidades y Sócrates argumenta:

"Pues, en nombre de esos mismos dioses de que ahora se trata, explícate, Melito, con más claridad. Porque no acierto a comprender si dices que enseño a reconocer que existen dioses - por donde, creyendo en ellos, no soy ateo, luego por aquí no soy culpable -, pero dioses distintos de los de la ciudad; o si lo que dices es que no creo en ningún dios, y que ésta es la doctrina que propago".$^{70}$ 
Sin embargo, Sócrates demuestra las contradicciones de sus acusadores en el juicio mismo y la acu- sación que éstos le hacen al afirmar que él no cree en los dioses:

"Pues, si creo en los demonios, según confiesas, y los démones son dioses, ahí está la prueba de lo que decía, de que nos propones enigmas y te diviertes a mi costa asegurando que no creo en los dioses, pero creo, puesto que creo en los démones. Y, si los démones son hijos de los dioses, hijos bastardos verdad es, dado que los hubieran con ninfas o aun con simples mortales, ¿qué hombre va a creer que hay hijos de dioses, pero no dioses? Tan absurdo sería creer que hay mulos, nacidos de caballos y asnos, pero no caballos ni asnos". ${ }^{71}$

Si se cree en los demonios y si los demonios son divinidades por lo tanto es incoherente afirmar que Sócrates no cree en los dioses. Ade- más, el filósofo atribuye a los dioses y las divinidades de su cultura su talento y su talante de filosofar:

"Extraño sería en mí, atenienses, que, después de haber guardado como buenos los puestos que los generales nombrados por vosotros me señalaran allá en Potidea, en Antípolis, en Delius, y después de haber expuesto mi vida tantas veces, llegara hoy a temer la muerte ni ninguna otra desgracia, cuando el dios de Delfos me ordena, según pienso, pasar mis días filosofando, examinándome y examinando a los demás; llegará, sí, a tener miedo de algo hasta el punto de abandonar mi puesto". ${ }^{72}$

Si él fuera absuelto por ese tribunal injusto y le impusieran la pena de dejar de enseñar y los diálogos filosóficos, él no podría escuchar primero a los jueces antes que a los dioses:

"si me absolviereis, pero me dijerais: 'Sócrates, vamos a rechazar la petición de Anito; te absolvemos, mas a condición de que en adelante no te ocupes en tus investigaciones ni en cuestiones de filosofía; $y$, caso de que reincidas y te lo descubran, morirás'; si me absolviereis, digo, en estas condiciones, yo os respondería: 'Mientras aliente y pueda no cesaré de consagrarme a la filosofía, de daros consejos". ${ }^{73}$ 
Es incoherente la acusación cuando se le quiere condenar por no creer en los dioses y Sócrates mismo arguye su actividad filosófica como un don y el talento otorgado por los dioses. La política, la cultura, la filosofía griega está fecundada de mitos...

La sociedad abierta también tiene sus mitos fundacionales. Se puede considerar que la sociedad abierta es un proyecto de la modernidad que también ha tenido sus mitos entre los que destaca el desarrollo y el progreso.

i) Karl Popper nos presenta su propuesta de la sociedad abierta que paradójicamente está cerrada a la alteridad, la diferencia cultural, los grupos étnicos que no son considerados aún parte de la sociedad abierta, cuya meta es la modernidad y toda pluralidad converge en este vértice. Sin embargo, la modernidad también está siendo juzgada por el despertar de una nueva sensibilidad de una nueva fase que va emergiendo subrepticiamente en la actualidad: la posmodernidad.

El auge de la modernidad se hizo patente con el desarrollo de las ciencias, la emancipación del conocimiento de todo dogmatismo, el racionalismo iniciado del siglo XVII y culminado por los filósofos de la Ilustración, la revolución industrial iniciada por Inglaterra la que se va a fundar sobre el sistema de la maquinización de los textiles, el ferrocarril y luego asumirá su protagonismo los Estados Unidos con la segunda revolución con la producción de automóviles, el petróleo y los bienes de consumo de masa. ${ }^{74}$

La primera revolución industrial se hizo con el carbón, el acero y los textiles (1850), la segunda revolución industrial se realizó con el progreso técnico de la mecánica, el automóvil, el avión, el petróleo, la química y la electricidad (1900), la tercera revolución se realizará en torno a los años 60 y corresponde al último período de la modernidad y los inicios de la posmodernidad, ésta se va a desarrollar con la electrotécnica, la telemática, la robótica, la biotecnología, la biomasa y el átomo. ${ }^{75}$

La crisis de la modernidad se ha ido vislumbrando por la crisis de la razón, de la idea de la verdad y de algunos valores que se sustentan en la misma modernidad, no así el valor de la autonomía y el lugar preponderante del individuo, que puede propiciar el individualismo muy impregnado en las sociedades liberales o neoliberales. El posmodernismo es un tipo de sensibilidad y un estilo de vida particular. ${ }^{76}$

La era posmoderna es el despertar de una nueva sensibilidad y no hacen falta voces proféticas que nos hacen pensar en un ajuste de cuentas porque las promesas optimistas de la técnica, la ciencia y el progreso, no han resuelto los problemas más importantes de la humanidad entre los que se encuentran la miseria, la 
violencia y los dramas más escalofriantes de guerras genocidas y fraticidas, las que han ocurrido dejando millones de seres humanos mutilados, lisiados, o en los cementerios. Nos basta con recordar Auschwitz, las dos guerras mundiales, la guerra de Afganistán, recientemente la invasión a Irak y también las guerras en Centroamérica. Todo esto en la era del resplandor de la razón. Todos estos hechos son lamentables en sí mismos, pero no hay que olvidar que también son deplorables los factores que han llevado a la humanidad a vivir estos acontecimientos.

Al parecer los graves conflictos humanos considerados sin precedente en la historia, han sido la parodia de la razón. Pero también hay un cuestionamiento de los objetivos que se había propuesto con un cierto radicalismo y de los resultados que se han obtenido:

\begin{abstract}
"Posmodernidad significa así una reelaboración, relectura o reinterpretación de la modernidad, es decir, un proceso teórico de puesta en cuestión al mismo tiempo que de radicalización de la categoría socio-histórica de modernidad, que se basa en el cambio sociocultural que el proceso de modernización ha originado en las sociedades avanzadas desde el punto de vista del proceso de la modernización". ${ }^{77}$
\end{abstract}

La posmodernidad se concreta en el rechazo de las cosmovisiones, de las explicaciones englobantes, totalizantes, que pretenden una visión integrada y coherente de los diversos aspectos de la realidad: "nada de respuestas últimas portadoras de sentido, nada de grandes proyectos, de ideologías dogmáticas y totalitarias: todas fracasaron. Lo mismo dígase de las utopías: progreso, armonía, democracia, paz, libertad...olvidemos!". ${ }^{78}$

No obstante, la posmodernidad no está enclaustrada en un compartimiento estanco que no pueda permear nuestros países latinoamericanos.

j) El planteamiento de Karl Popper nos cuestiona y nos hace entrar en el debate para tratar el tema de la coexistencia, la convivencia de las sociedades abiertas y la pluralidad de identidades. No podemos perder de vista que hay aspectos comunes entre lo que K. Popper califica de sociedades abiertas y las que él considera sociedades cerradas. En principio hay que considerar que no existe cultura o civilización que no haya convivido con diversidad de etnias, tribus, y si no se puede considerar relaciones sustentadas en el derecho, la fuerza de la costumbre y la tradición han constituido de hecho un derecho consuetudinario. Tanto en las sociedades abiertas como en las cerradas, hay una fuerza social que se hace sentir por el hábito, la tradición, las costumbres, los relatos míticos, 
expresiones simbólicas. Toda sociedad posee estas notas que van configurando su identidad. Es más, hay rasgos nacionalistas en muchas sociedades modernas, consideradas abiertas, que se caracterizan por un fuerte nacionalismo, una reivindicación de su cultura, de sus tradiciones ancestrales, identificándose con rasgos hasta biológicos o pro- pios del lugar. Se considera que haber nacido en un territorio o país específico, por muy adelantado y moderno que sea, marca una diferencia y una estela de dignidad y de orgullo nacional. El tema de las sociedades abiertas y las sociedades cerradas es central para entrar en diálogo y la tolerancia entre la pluralidad de identidades.

\section{4) Implicaciones para la construcción de un mundo mejor desde América Latina.}

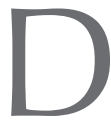
espués de haber hecho un análisis de los planteamientos de Karl Popper desde la realidad latinoamericana, nos parece importante destacar algunas implicaciones.

a) La democracia occidental debe priorizar en su programa político el tema de la justa distribución de la riqueza en el mundo de cara a resolver el problema de la pobreza y la exclusión social. Visto desde la realidad latinoamericana, la verdadera democracia es la que implica un desarrollo económico y social con justicia y equidad para la sociedad en su conjunto.

b) El fortalecimiento institucional es una condición imprescindible para resolver los problemas de la pobreza, la exclusión social, el empleo, la delincuencia, la violencia, los servicios públicos e infraestructura, la corrupción, etc. Desde esta perspectiva, la democracia latinoamericana se ve obligada a repensar políticamente la constitución del Estado de bienestar social y en Centroamérica, este es un desafío regional, es decir, es necesario la constitución de un Estado de bienestar social regional.

c) Las aperturas comerciales, económicas y financieras, así como las relaciones políticas globales en una sociedad democrática no puede cerrarse a la alteridad cultural, ni tampoco cerrarse al pluralismo y la diversidad étnica. La auténtica democracia tiene como exigencia la adopción de una postura pluralista y de convivencia con la diversidad cultural.

d) Un factor determinante para la sociedad latinoamericana es la educación, pero no cualquier educación, sino la que forma la conciencia y la sensibilidad 
con responsabilidad humana y social, de tal forma que los ciudadanos latinoamericanos asumamos los grandes desafíos que ha provocado el mundo moderno en transición a la posmodernidad.

e) Al hablar de la constitución de un Estado de bienestar social centroamericano, no pretendemos aplastar la sociedad civil. Hay que favorecer los movimientos sociales para que florezca una sociedad civil revitalizada. Es imprescindible la existencia de movimientos de los migrantes, de los derechos humanos, de la equidad de género, de la conservación y el diálogo entre las culturas, a favor de la paz, así como de la conservación del medio ambiente y la biodiversidad, también foros internacionales como el foro de Porto Alegre para defender los países que están siendo arrollados por la globalización económica y financiera, etc. La sociedad civil tiene que jugar un rol protagónico en la región centroamericana para consolidar una auténtica democracia.

f) La sociedad abierta de Karl Popper nos hace pensar en una sociedad abierta alternativa, en la que sí se realice el ideal del pleno reconocimiento de la dignidad humana, el mutuo reconocimiento de los derechos entre los seres humanos, la aceptación recíproca de las diferencias, la convivencia pacífica y la coexistencia de la pluralidad cultural, la participación activa de todos los seres humanos de los bienes de la creación, el recurso del diálogo y el ejercicio auténtico de la democracia para el mutuo entendimiento y la aceptación recíproca tolerante.

g) Muchas otras implicaciones podemos educir del planteamiento que nos hace Karl Popper desde la realidad latinoamericana, sin embargo, lo que hemos intentado hacer es hacer un esfuerzo de indicar posibles vías de reflexión para un futuro inmediato. Este es un humilde aporte que intenta sumarse a la búsqueda y la construcción de un mundo mejor.

Recapitulando lo que hemos tratado en el presente trabajo. Iniciamos haciendo un esbozo del contexto actual de la sociedad centroamericana, luego hemos destacado el proceso de aperturas globales y la constitución de la sociedad red global en la cual Centroamérica está incluida. Desde este contexto retomamos los aportes que hace Karl Popper y su filosofía moral porque es un autor liberal emblemático y consideramos que sus planteamientos recopilan algunos de los argumentos en la sociedad occidental que han influido mucho en la actualidad.

Karl Popper escribe en inglés La sociedad abierta y sus enemigos en 1945 y es traducida al español en 1957, es su obra filosófica política de mayor envergadura. Su obra En 
busca de un mundo mejor aparece originalmente en inglés en 1992 y es traducida al castellano en 1994. Hemos subrayado los argumentos que tienen una mayor difusión en un contexto liberal o neoliberal, los cuales dicho autor ha ido elaborando durante el transcurso de su producción filosófica política en el siglo pasado por esta razón hemos escogido dos de sus obras ampliamente conocidas. Sin lugar a dudas, Karl Popper es un autor emblemático del pensamiento liberal y sus argumentos también son esgrimidos por los pensadores neliberales y hay filósofos que sostienen que también por los socialistas reformistas. ${ }^{79}$

Karl Popper es representante del racionalismo crítico que propone la falsación y no la verificación para la validez de la ciencia. La ciencia se va construyendo mediante el proceso deductivo y se valida con la crítica. La ciencia es un cúmulo de conocimientos hipotético y conjetural. ${ }^{80} \mathrm{El}$ verdadero conocimiento científico es el que se somete a la falsación, es decir, que ha superado la fase de demostrarse lo contrario a lo que se plantea, se prueba si las hipótesis planteadas son falsables:

"Popper defiende la idea de que todo conocimiento científico es provisional y falible y que el progreso de la ciencia se basa en un proceso continuo de refutación de teorías y ensayos de nuevas teorías que inmediatamente son expuestas a la refutación. La base del falibilismo popperiano reside en su crítica de la inducción, inspirada en Hume. En síntesis, para Popper la inducción es un proceso lógicamente injustificable, psicológicamente imposible y metodológicamente irrelevante: el descubrimiento científico no procede de ensayos y eliminación de errores. Lo importante en el método científico no procede por inducción, sino a través de un proceso de ensayos y eliminación de errores. Lo importante en el método científico no es verificar teoría, sino lanzar hipótesis que merezcan ser sometidas a contrastación empírica y puedan ser refutadas por los hechos" ${ }^{81}$

Nosotros hemos aplicado dicho criterio al planteamiento filosófico moral que nos hace Karl Popper contrastándolo con los hechos y los datos que nos arrojan las ciencias sociales. Lo cual nos ha arrojado grandes líneas maestras para seguir pensando y reflexionando sobre la sociedad abierta global sin claudicar a la búsqueda de un mundo mejor.
Karl Popper no ha parecido un autor liberal sugerente porque al proponer su proyecto de la sociedad abierta toca temas fundamentales como la economía de mercado y el crecimiento económico, la pobreza, la educación, la democracia, el Estado de bienestar, etc. Todas estas temáticas son de gran actualidad dado el ambiente neoliberal en 
muchos de nuestros países latinoamericanos.

Hemos hecho una lectura crítica de sus aportes y no podemos eludir el hecho que su planteamiento suscita grandes interrogantes que hemos expresado en el desarrollo de este trabajo. Nos percatamos que su propuesta de continuar con un modelo de crecimiento ilimitado es inviable de cara a los grandes desequilibrios ecológicos que genera el modelo neoliberal. La democracia muchas veces se limita a los aspectos formales y la realización de los derechos políticos civiles, sin tomar en cuenta de la misma manera los derechos económicos y sociales. Además nos abre al mutuo enriquecimiento cultural al tener esas fricciones culturales que han existido en la historia de la humanidad.

Hemos subrayado los límites de la sociedad abierta que nos propone Karl Popper, con respecto a la crítica que hace al Estado de bienestar nos hace caer en la cuenta de la necesidad de la participación activa de los Estados nacionales porque los mercados no resuelven todos los problemas, la visión historicista que él critica también ha sido impregnada en su concepción evolutiva de las civilizaciones hasta llegar al punto de constituir la sociedad abierta, la visión desarrollista que está implícita en la sociedad abierta también es criticable por los procesos de dependencia y subdesarrollo que conlleva, las asimetrías y las diferencias sociales son legitimadas en su proyecto de la sociedad abierta. Karl Popper no pondera también el impacto de la modernidad y sus consecuencias, ni se percibe en su reflexión filosófica la autocrítica con respecto a rasgos etnocéntricos que denota la sociedad abierta. Desde esta perspectiva, no está demás subrayar la evidente paradoja de la sociedad abierta cerrada a la alteridad y la diversidad étnica, muchas de ellas consideradas como sociedades cerradas.

Finalmente hemos retomado aspectos fundamentales relacionados con el crecimiento económico, el empobrecimiento y la democracia en América Latina. Aspectos sugeridos por Karl Popper en el desarrollo de su pensamiento filosófico político. Retomamos datos de los estudios realizados por el PNUD y otras fuentes. De tal manera que la sociedad red global que se va configurando de manera casi inadvertida pero al mismo tiempo eficazmente, tiene sus grandes problemáticas que no se pueden eludir y que nos hacen siempre ir en la búsqueda de construir un mundo mejor, una sociedad red global justa, solidaria y fraterna. 

das para el Desarrollo (PNUD), El abismo de la desigualdad. Informe sobre desarrollo humano 1992, Cristianisme i Justicia, Barcelona, 1992, p. 5. tectura Imposible, Uruguay, 2006, p. 216.

Social Watch, Informe 2006. Arquitectura Imposible, Uruguay, 2006, p. 206.

13 Revista Proceso, Año 28, $\mathrm{N}^{\circ} 1239$, Mayo 2, 2007, p. 5.

14 Social Watch, Informe 2006. Arquitectura Imposible, Uruguay, 2006, p. 207.

3 Cfr. Programa de las Naciones Unidas para el Desarrollo (PNUD), Resumen informe sobre desarrollo humano 2005, p.15.

$4 \quad$ Ibíd., p.18.

5 Tabla elaborada en base a los datos proporcionados por el gráfico $n^{\circ} 4$ que aparece en el estudio del Programa de las Naciones Unidas para el Desarrollo (PNUD), La Democracia en América Latina. Hacia una democracia de ciudadanas y ciudadanos, Aguilar, Altea, Taurus, Alfaguara, S.A., Buenos Aires, 2004, p. 124.

6 Cfr. Helio Gallardo, Revista Pasos, San José - Costa Rica, Enero - Febrero de 1988, $\mathrm{N}^{\circ} 15$, p. 1.

$7 \quad$ Luis Alvarenga, "Las necesidades de otro estilo de desarrollo: una lectura ética del segundo informe del PNUD sobre Centroamérica”, en ECA, Revista de extensión cultural de la Universidad Centroamericana "José Simeón Cañas”, Año LVIII, Septiembre de 2003, p. 922.

8 Ibíd., p.923.

$9 \quad$ Social Watch, Informe 2006. Arquitectura Imposible, Uruguay, 2006, p. 202.

10 Social Watch, Informe 2006. Arquitectura Imposible, Uruguay, 2006, p. 216. para el Desarrollo (PNUD), La Democracia en América Latina. Hacia una democracia de ciudadanas y ciudadanos, Aguilar, Altea, Taurus, Alfaguara, S.A., Buenos Aires, 2004, p. 173.

21 Esta tabla ha sido elaborada en base al gráfico $\mathrm{N}^{\circ} 9$ que aparece en el estudio del Programa de las Naciones Unidas para el Desarrollo (PNUD), La Democracia en América Latina. Hacia una democracia de ciudadanas y ciudadanos, Op. cit., p. 193.

22 Cfr. Manuel Castells, La era de la información. economía, sociedad 


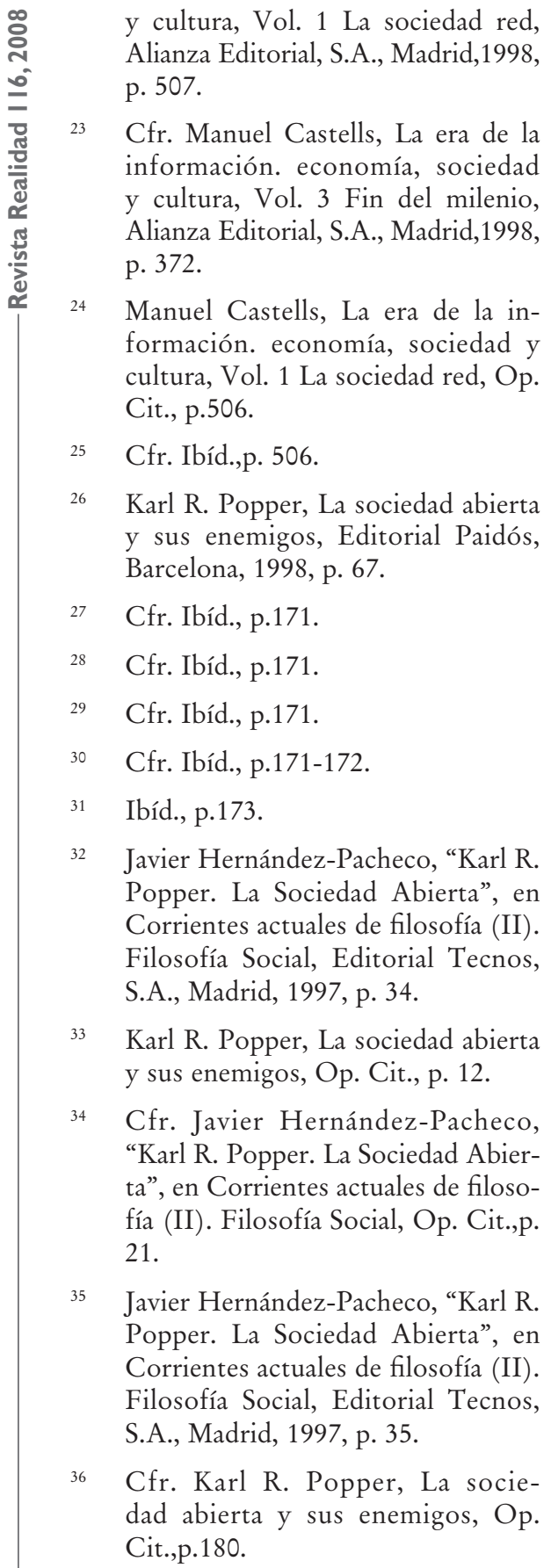

amos a desarrollar primero lo que implica el planteamiento de la sociedad abierta. Luego vamos a aplicar el criterio de falsación o de refutación del mismo desde la realidad de nuestro mundo actual. De esta manera seremos coherentes con el autor que inspira nuestra reflexión quien es al mismo tiempo, unos de los representantes del racionalismo crítico y del criterio de falsabilidad (Cfr. Miguel A. Quintanilla (Director), "Popper, Karl Raimond", en Diccionario de filosofía contemporánea, Ediciones Sígueme, Salamanca, 1985, pp. 384-385). Según el planteamiento de Karl Popper, una teoría científica es aceptable si es falsable, es decir, la ciencia consiste no solamente en la confirmación de hipótesis, sino en pruebas para ver si las hipótesis son falsables (Cfr. José Ferrater Mora, Diccionario de Filosofía, Tomo III (K-p), Editorial Ariel, S.A., Barcelona, 2001, pp. 2841-2843). La constatación de una teoría no consiste en su verificación, es decir, en mostrar hechos que la confirmen, sino en demostrar hechos que la desmienten para invalidarla: "Una teoría es falsada cuando se descubre un hecho que la desmiente o, más específicamente, cuando se puede deducir de la teoría un enunciado singular predictivo que no la verifica" (José Ferrater Mora, Diccionario de Filosofía, Tomo II (E-J), Editorial Ariel, S.A., Barcelona, 2004, pp. 1213).

${ }^{41}$ Karl Popper, En busca de un mundo mejor, Ediciones Paidós Ibérica, S.A., Barcelona, 1996, p.11.

42 Ibíd., p.11. 
Ibíd., p.273.

Ibíd. 6, p.270.

Ibíd., p.273.

Ibíd., p.274.

Ibíd., p.275.

Ibíd., p.276.

Ibíd., p.276.

Ibíd., p.278.

Ibíd., p.279.

Cfr. Ibíd., 1996, p.202.

Cfr. Ibíd., p.203.

Ibíd., p.204.

Cfr. Ibíd., p.19.

Ibíd., p.69.

Ibíd., p.69.

Cfr. Ibíd., pp. 133-164.

Sin pretender caer en una contradicción in terminis al hablar de choque cultural y actitud de diálogo y encuentro.

Cfr. Dean Brackley, "Hacia un ethos radical”, en Revista Latinoamericana de Teología, Mayo-Agosto de 1998. También algunos escritos inéditos del mismo autor en donde se trata el ethos pormoderno.

${ }_{61}$ Burleigh Taylor Wilkings, ¿Tiene la historia algún sentido? Una crítica a la filosofía de la historia de Popper, Fondo de Cultura Económia, México, D.F., 1983, p. 25.

62 Ibíd., p. 26.

José Ferrater Mora, Diccionario de Filosofía de Bolsillo I -Z, Alianza Editorial, Madrid, 1992, p. 528.

Ibíd., p. 530.

Jean-Pierre Vernant, El universo, los dioses, los hombres. El relato de los mitos griegos, Editorial Anagrama, S.A., Barcelona, 2000, pp. 15-16.

Cfr. G. S. Kirk, El mito. Su significado y funciones en la Antigüedad y otras culturas, Ediciones Piados Ibérica, S.A., Barcelona, 1985, p.100.

http://www.portalplanetasedna.com. ar/mitologia_griega1.htm\#zeus

Cfr. Feliciano Blázquez, Diccionario de Mitología. Dioses, héroes, mitos y leyendas, Editorial Verbo Divino, Navarra, España, p. 919.

Platón, Apología de Sócrates. Critón - Banquete, Biblioteca de Filosofía, Mestas Ediciones, Madrid, 2003, p. 32. posmodernidad y 'nueva era'”, en Revista Medellín, vol XXIII - $\mathrm{N}^{\circ}$ 92/Diciembre 97, Santafé de Bogotá, D.C., Colombia, p. 611. 
Administración y Economía, Person Educación de Colombia, LTDA., Bogotá, 2002, p.35. diccionario filosófico, Editorial Verbo Divino, Navarra, 1991, p.229.

81 Miguel Angel Quintanilla, Breve dicCfr. Cesar Augusto Bernal T., Metodología de la Investigación para la cionario filosófico, Op. cit., p.227. 